\title{
Development of a median sternotomy simulation model for cardiac surgery training
}

\author{
Thin Xuan Vo, MD, MSc, ${ }^{a}$ Nadzir Juanda, MD, ${ }^{a}$ Janet Ngu, MD, MSc, ${ }^{a}$ Nada Gawad, MD, MAEd, ${ }^{b}$ \\ Kathy LaBelle, ${ }^{c}$ and Fraser D. Rubens, MD, MSc, FACS, FRCSC
}

\section{ABSTRACT}

Objective: We sought to develop a simulation model to train resident physicians in the performance of a median sternotomy.

Methods: A modified Delphi consensus process was used with cardiac surgery staff to develop a 20-point checklist for the safe performance of a median sternotomy. Thirteen junior cardiac surgery trainees from across Canada participated in this study to assess the simulation model. Trainees performed the sternotomy before and after reviewing an instructional video. Two senior cardiac surgery resident physicians assessed the participants with the checklist during each session. An entry and exit questionnaire was given to the participants to evaluate the simulation model.

Results: Participants scored higher after the training (14.3 \pm 2.0$)$ compared with before training $(8.0 \pm 3.1)(P<.001)$. The mean duration of time for participants to complete the sternotomy was shorter before training (188 \pm 52 seconds vs $228 \pm 58$ seconds; $P=.003$ ). The checklist interrater reliability was $\kappa=0.47$ (moderate) for before training and $\kappa=0.37$ (fair) for after training. All study participants rated the simulation sessions as very useful or extremely useful.

Conclusions: Using the simulation model, training video, and checklist, trainees were able to improve their skill in performing a median sternotomy. This improvement was associated with longer times to complete all procedure steps. Rater training may further improve interrater reliability. Our median sternotomy checklist and simulation model can be adopted for the technical skills training of future cardiac surgery trainees. (JTCVS Techniques 2020;2:109-16)

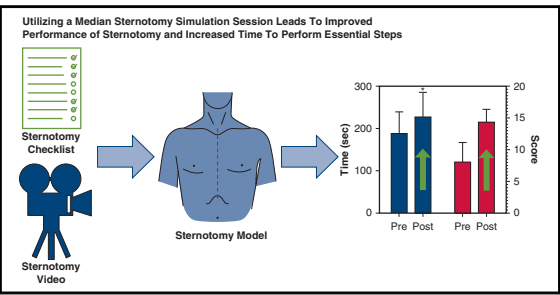

A sternotomy model, video, and checklist leads to performance improvement.

CENTRAL MESSAGE

An inexpensive simulation model and didactic video helps trainees improve their technical performance on the essential skill of median sternotomy.

\section{PERSPECTIVE}

Simulation affords trainees increased opportunities to develop their skills in a safe environment. Checklists allow trainees to be assessed in their skill performance while also providing a study aid. Our sternotomy model and checklist led to improved performance in this essential skillset. This inexpensive model and checklist can potentially be incorporated into other cardiothoracic training programs.

See Commentaries on pages 117 and 119.
From the aivision of Cardiac Surgery, Department of Surgery, University of Ottawa Heart Institute, Ottawa, Ontario, Canada; ${ }^{\mathrm{b} D i v i s i o n}$ of General Surgery, Department of Surgery, University of Ottawa, Ottawa, Ontario, Canada; and the ${ }^{c}$ University of Ottawa Skills and Simulation Centre, Ottawa, Ontario, Canada.

Received for publication Feb 4, 2020; revisions received Feb 4, 2020; accepted for publication March 8, 2020; available ahead of print April 5, 2020.

Address for reprints: Fraser D. Rubens, MD, MSc, FACS, FRCSC, University of Ottawa Heart Institute, 40 Ruskin St, Ottawa, Ontario K1Y 4W7, Canada (E-mail: FRubens@uOttawa.ca).

2666-2507

Copyright $\odot 2020$ The Authors. Published by Elsevier Inc. on behalf of The American Association for Thoracic Surgery. This is an open access article under the CC BY-NCND license (http://creativecommons.org/licenses/by-nc-nd/4.0/).

https://doi.org/10.1016/j.xjtc.2020.03.007
Simulation-based training is being increasingly incorporated in cardiac surgery training programs across North America. ${ }^{1-6}$ The simulation lab is an ideal arena for the acquisition of technical skills because it allows for deliberate practice in a low stakes, low stress, and safe environment. ${ }^{1,7,8}$ As more surgical residency programs transition from a time-based training model toward a competency-based medical education model, trainees will require more objective measures of performance and competency as well as validated assessment tools for these 
measures. ${ }^{9}$ Task-specific checklists, global rating scales, and objective structured assessment of technical skills are some of the assessment tools being employed in the assessment of surgical trainees. ${ }^{9,10}$ In particular, task-specific checklists allow the trainee to be assessed throughout pivotal points of the procedure and also act as a study aid for reviewing the procedure. ${ }^{9,10}$

Median sternotomy is an essential and foundational skill for cardiac surgery training. Although the median sternotomy is learned during the early stages of training; that is, postgraduate years 1 and $2,{ }^{11}$ it is an essential skill to master. A poorly performed sternotomy may have devastating consequences, including sternal dehiscence, deep sternal wound infection, and mediastinitis. ${ }^{12}$

Although many cardiac surgical training programs have focused on the development of skills such as vascular anastomosis, thoracotomy, internal thoracic artery harvest, initiation of cardiopulmonary bypass, and cannulation, there is a paucity of literature regarding the development of models for the simulation of and assessment of median sternotomy. ${ }^{1,5,6,13,14}$ Even high-fidelity models that mimic operating in the pericardial cavity have simulated the performance of a sternotomy. ${ }^{14}$

The objective of the current study was to develop an inexpensive simulation model for the practice of median sternotomy and gather preliminary validity evidence for its use in cardiac surgery technical skills training. The study was undertaken during an annual nationwide boot camp for junior trainees enrolled in cardiac surgery residency training programs across Canada.

\section{METHODS}

\section{Setting and Participants}

The Canadian Cardiac Surgery Junior Resident Bootcamp is an annual training week outside of the formal residency curriculum for junior trainees enrolled in cardiac surgery training programs across Canada. The Bootcamp encompasses both simulation-based and didactic-based sessions in fundamental topics and skills related to cardiac surgery. As part of the Bootcamp, a sternotomy simulation session was conducted. The sternotomy session consisted of a sternotomy simulation with our developed median sternotomy model, a teaching video (Video 1), which highlighted and modeled our median sternotomy checklist, and repeat sternotomy simulation after viewing the video and review of the checklist (Video 2). Thirteen resident participants enrolled in this study in July 2017. The study was reviewed by the institutional ethics committee.

\section{Development of Median Sternotomy Checklist}

We used a modified Delphi consensus process ${ }^{15-17}$ to create a checklist. An initial checklist was created by 2 senior cardiac surgery resident physicians. The checklist was then distributed to an expert panel consisting of 4 staff cardiac surgeons for review. Changes were made in the checklist if at least 3 out of the 4 surgeons made similar recommendations. The revised checklist was re-presented to the faculty surgeons and a $75 \%$ panel agreement had to be obtained for every item on the checklist. After 2 rounds of review, a final checklist was created (Table 1). The final version of the checklist consisted of a total of 20 steps subcategorized into 4 sections.

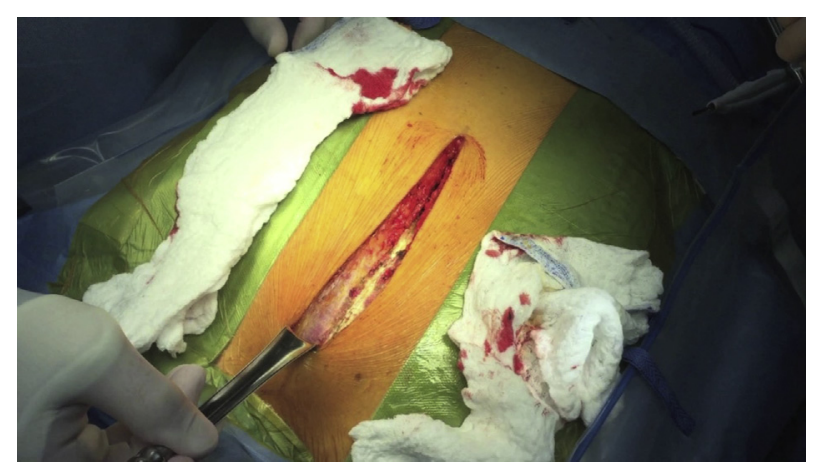

VIDEO 1. An intraoperative instructional video demonstrating the steps of median sternotomy. This video was used as guide for the performance of median sternotomy for study participants and trainees. Video available at: https://www.jtcvs.org/article/S2666-2507(20)30152-8/fulltext.

\section{Development of Video on Sternotomy}

A 5-minute video prepared using intraoperative footage with a real patient was developed (Video 1). The video was edited to highlight each of the steps on the median sternotomy checklist. Verbal consent was obtained from the patient before the recording of the procedure.

\section{Conduct of Participant Assessment}

Participants were assessed during the sternotomy simulation before (Pre) and after viewing an instructional video (Post). Two senior residents independently observed each participant during the simulation, recording the time required to complete the task and the achieved score on the checklist. Duration of the task was defined as the time elapsed from incision to time of completion.

\section{Entry and Exit Questionnaires}

All candidates completed an entry questionnaire that included demographic information before the session. An exit questionnaire was given to the participants to assess their anxiety and preparedness regarding the performance of median sternotomy. Participants were also asked the following: feedback regarding the simulation model, usefulness of the simulation session (5-point Likert scale), perception of how realistic they found the model (5-point Likert scale), and individual feedback in terms of usefulness of the entire session. Finally, participants were given the

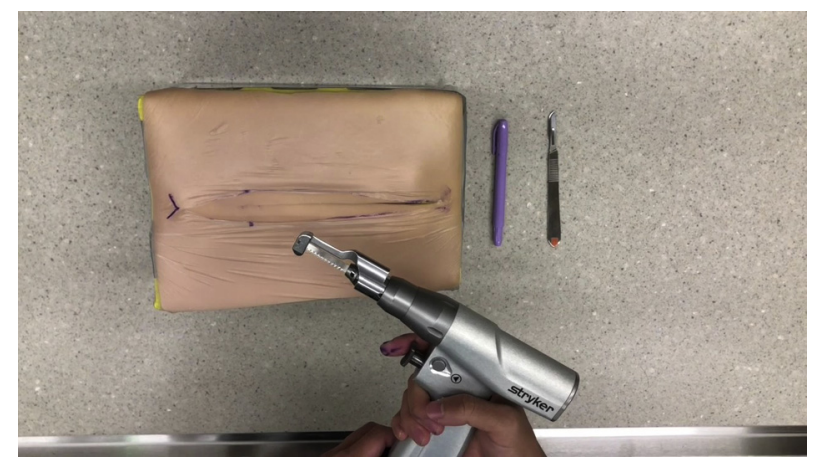

VIDEO 2. A video demonstrating the use of the sternotomy model. Video available at: https://www.jtcvs.org/article/S2666-2507(20)30152-8/ fulltext. 
TABLE 1. The median sternotomy checklist

\section{Sternotomy Checklist Marking Scheme (Final Version)}

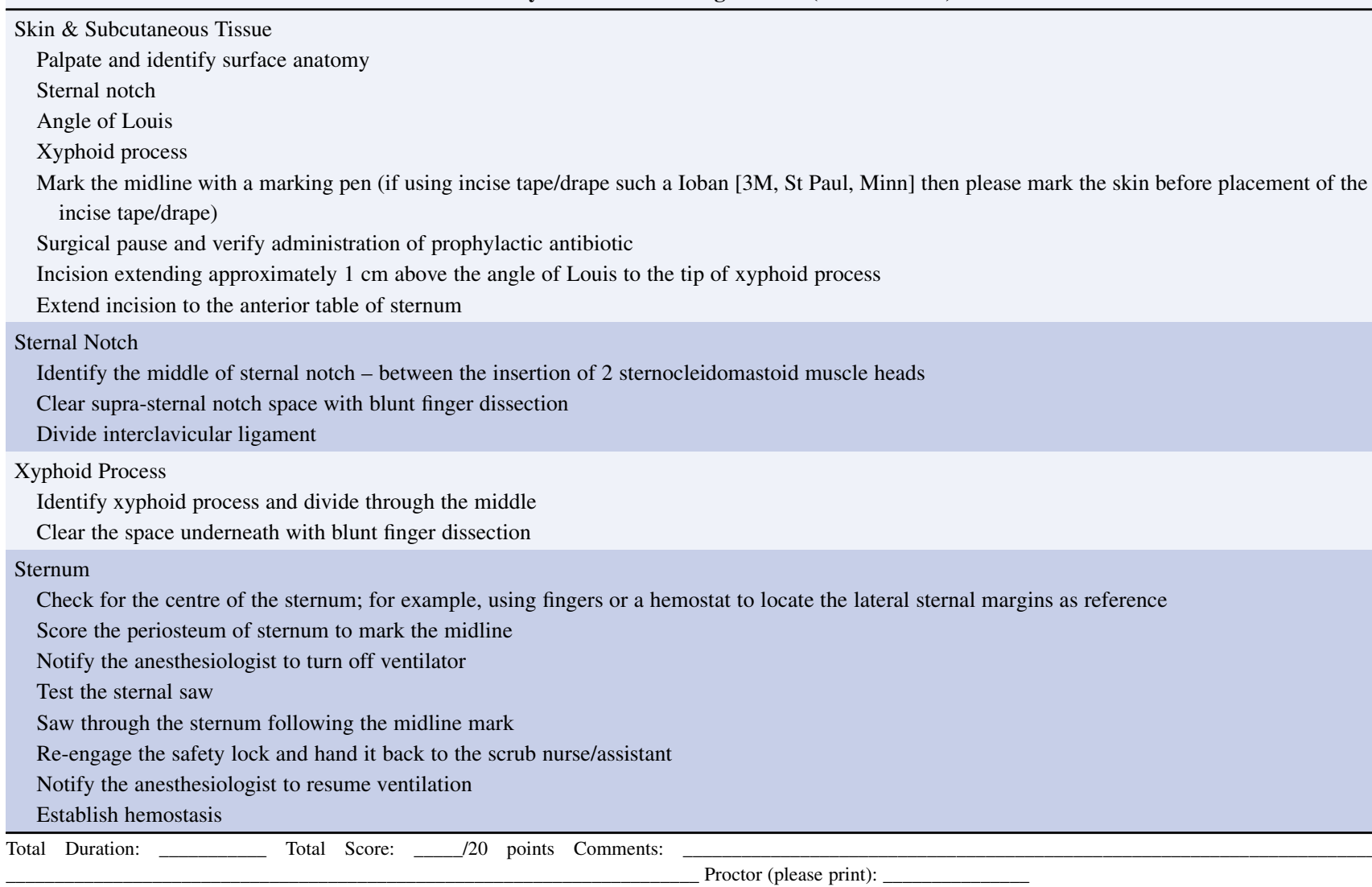

opportunity to provide open-ended qualitative feedback as part of the exit questionnaire. Questionnaires are available in Tables 2 and 3.

\section{Creating a Benchtop Sternotomy Model}

The sternotomy model was created using an acrylic box measuring $20 \mathrm{~cm}$ long $\times 12 \mathrm{~cm}$ wide and $15 \mathrm{~cm}$ deep. A sternum model (Sternum with cartilage 20PCF Solid Foam; Sawbones, Vashon Island, Wash) was placed on a foam floor mat ( $3 \mathrm{~mm}$ thick) and the outline was cut out to encompass the sternal bone model into the foam sheet. A popsicle stick was placed on each side of the sternum approximately 0.5 to $1 \mathrm{~cm}$ lateral to the sternal edge and secured with duct tape. A small piece of artificial skin (Dragon Skin 10; Smooth-On, Macungie, Pa) outlining the sternal notch was stapled adjacent to the sternal notch to accentuate it for trainees to palpate. Another layer of artificial skin was then layered above the sternum. The layers were then secured together with brass split pins. The water-filled balloon was placed in the acrylic box and cling film was placed over the box to simulate the heart with pericardium above it. The artificial chest wall containing all pertinent layers and artificial sternum was then put on top of the acrylic box, which was secured tightly with tape. Images of the model are available in Figure 1, $A-H$.

The materials required to perform the sternotomy simulation are displayed in Figure 2. These materials include the sternotomy model, a marking pen (acting as both a marking pen and cautery tip), a 10-blade scalpel, and a sternal saw (Stryker, Kalamazoo, Mich).

\section{Data Analysis and Interrater Reliability}

Interrater reliability was assessed using the kappa statistic. ${ }^{18}$ Characterization of agreement for interrater reliability was based on recommendations of Landis and colleagues ${ }^{19}$ as follows: values $\leq 0$ as indicating no agreement, 0.01 to 0.20 as none to slight, 0.21 to 0.40 as fair, 0.41 to 0.60 as moderate, 0.61 to 0.80 as substantial, and 0.81 to 1.00 as almost perfect agreement. ${ }^{19}$

Normality of the data was tested using the Shappiro-Wilk test. The Student $t$ test was used to analyze the continuous data. Analyses were performed using STATA version 14.2 (StataCorp, College Station, Tex).

\section{RESULTS \\ Participants}

Participant demographic data are noted in Table 4. All study participants were enrolled in Royal College of Physicians and Surgeons of Canada 6-year cardiac surgery training programs from across Canada.

\section{Performance of Sternotomy and Checklist Reliability}

Participants had a significantly higher mean score on the median sternotomy checklist Post compared with Pre $(14.3 \pm 2.0$ vs $8.0 \pm 3.1 ; P<.001)$ (Figure 3$)$. The mean duration of time for participants to complete the sternotomy was lower Pre versus Post (188 \pm 52 seconds vs $228 \pm 58$ seconds; $P=.003$ ) (Figure 3 ). All individual participants seemed to follow a similar pattern of increasing time and score from Pre to Post (Figure 3). The checklist interrater reliability was $\kappa=0.47$ (moderate) for Pre and $\kappa=0.37$ (fair) for Post. 
TABLE 2. Pre video and sternotomy session questionnaire

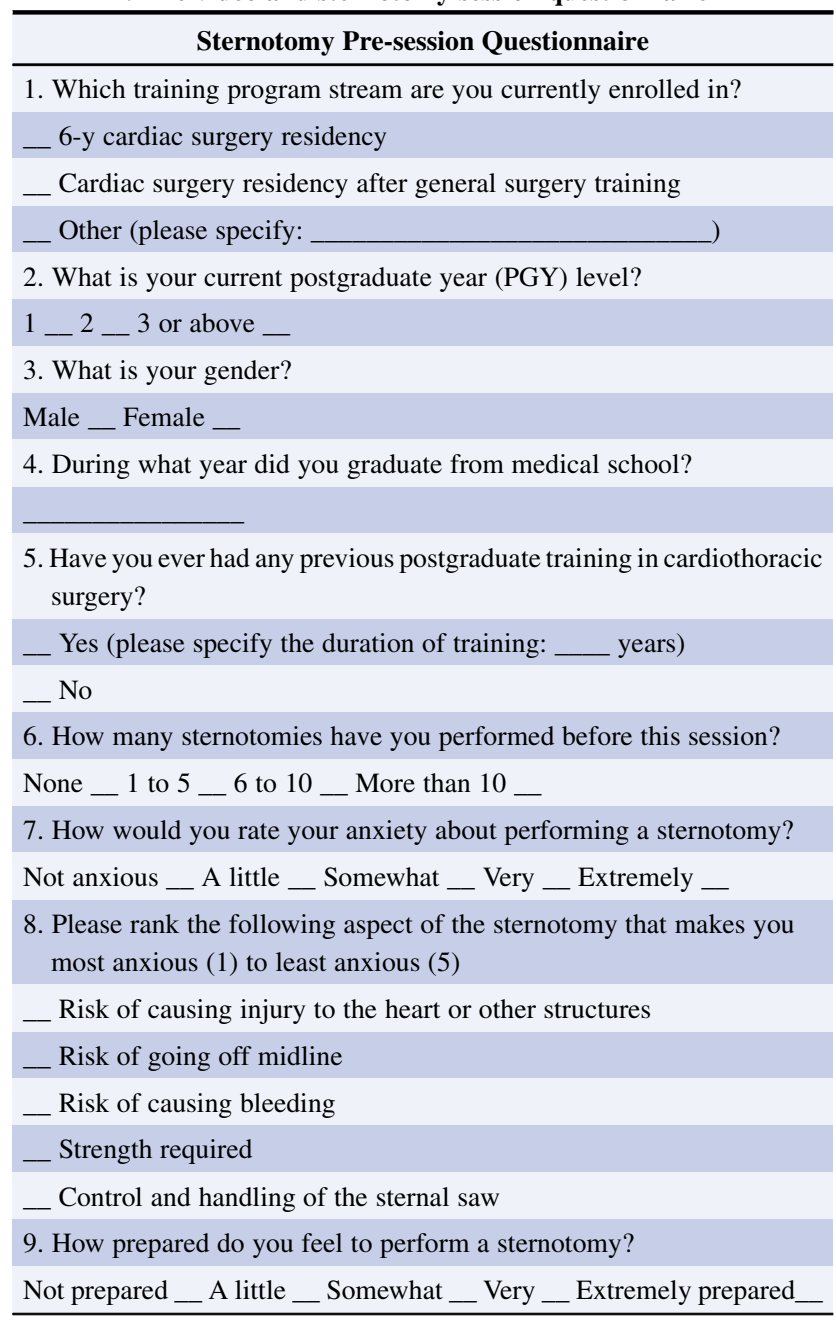

\section{Entry and Exit Questionnaires}

On the entry questionnaire, participants were surveyed regarding their anxiety toward the performance of median sternotomy. Fifty percent of participants ranked causing injury to the heart or other structures and $50 \%$ of participants ranked going off midline as the greatest sources of anxiety. Thirty-eight percent of participants rated their anxiety level for performing a median sternotomy as a little anxious on their entry questionnaire. Twenty-three percent of participants were equally somewhat anxious and very anxious. Only one participant was not anxious and only 1 participant was extremely anxious.

On the exit questionnaire, $100 \%$ of participants rated the simulation sessions as very useful or extremely useful. Even participants who had done 10 or more sternotomies before the session found that the session was either very useful or extremely useful. Eight participants $(62 \%)$ described the median sternotomy simulation model as very realistic, four participants $(31 \%)$ described it as somewhat realistic, and only 1 participant described it as a little realistic. Most
TABLE 3. Post video and sternotomy session questionnaire

\begin{tabular}{|c|}
\hline Sternotomy Post-session Questionnaire \\
\hline 1. How useful did you find this training session? \\
\hline Not at all__ A little__ Somewhat__ Very _ Extremely _ \\
\hline 2. How would you rate your anxiety about performing a sternotomy? \\
\hline Not anxious _ A little _ Somewhat _ Very _ Extremely _ \\
\hline 3. How prepared do you feel to perform a sternotomy? \\
\hline Not prepared__ A little __ Somewhat _ Very _ Extremely prepared __ \\
\hline $\begin{array}{l}\text { 4. Please rank the following elements of the training session most useful } \\
\text { (1) to least useful (3) }\end{array}$ \\
\hline __ Didactic video/lecture \\
\hline Practice on the sternotomy model \\
\hline __ Debriefing by the evaluator \\
\hline 5. How realistic is the sternotomy simulation model? \\
\hline Not at all _ A little __ Somewhat _ Very _ Extremely _ \\
\hline $\begin{array}{l}\text { 6. Please provide comments/feedbacks/suggestions regarding the } \\
\text { sternotomy session. }\end{array}$ \\
\hline
\end{tabular}

participants $(70 \%)$ ranked the simulation model as the most useful element of the training session compared with the individual feedback and didactic video. Based on the commentary of the questionnaire and feedback of the participants, participants found the hands-on component of the session the most useful.

\section{DISCUSSION}

As surgical residency programs transition toward a competency-based paradigm, more learning will occur outside of the traditional clinical environment. Previous studies have demonstrated improvements in cardiac surgery-related technical and procedural skills after practice in the simulation laboratory. ${ }^{1,2,6}$ This study found that an inexpensive median sternotomy simulation model paired with an instructional video led to improvement in procedural performance reflected by improved scores on our checklist.

We found an increased duration of time to perform the median sternotomy during Post compared with Pre, after participants had an opportunity to review the checklist and see the instructional sternotomy video. This increased time may have been related to increased cognitive load as participants tried to recall and mentally process the newly learned steps. Dreyfus and Dreyfus ${ }^{21}$ support this with their theory of skill acquisition. Because participants in the simulation sternotomy session were likely in the Novice to Competent level of skill acquisition, a significant amount of cognitive processing, including effort and attention, is attributed to each detail and step of the skill. ${ }^{20,21}$ Furthermore, participants may have been spending more time performing previously missed steps.

The creation of a procedural checklist for training median sternotomy serves 2 purposes in this setting; first, the 

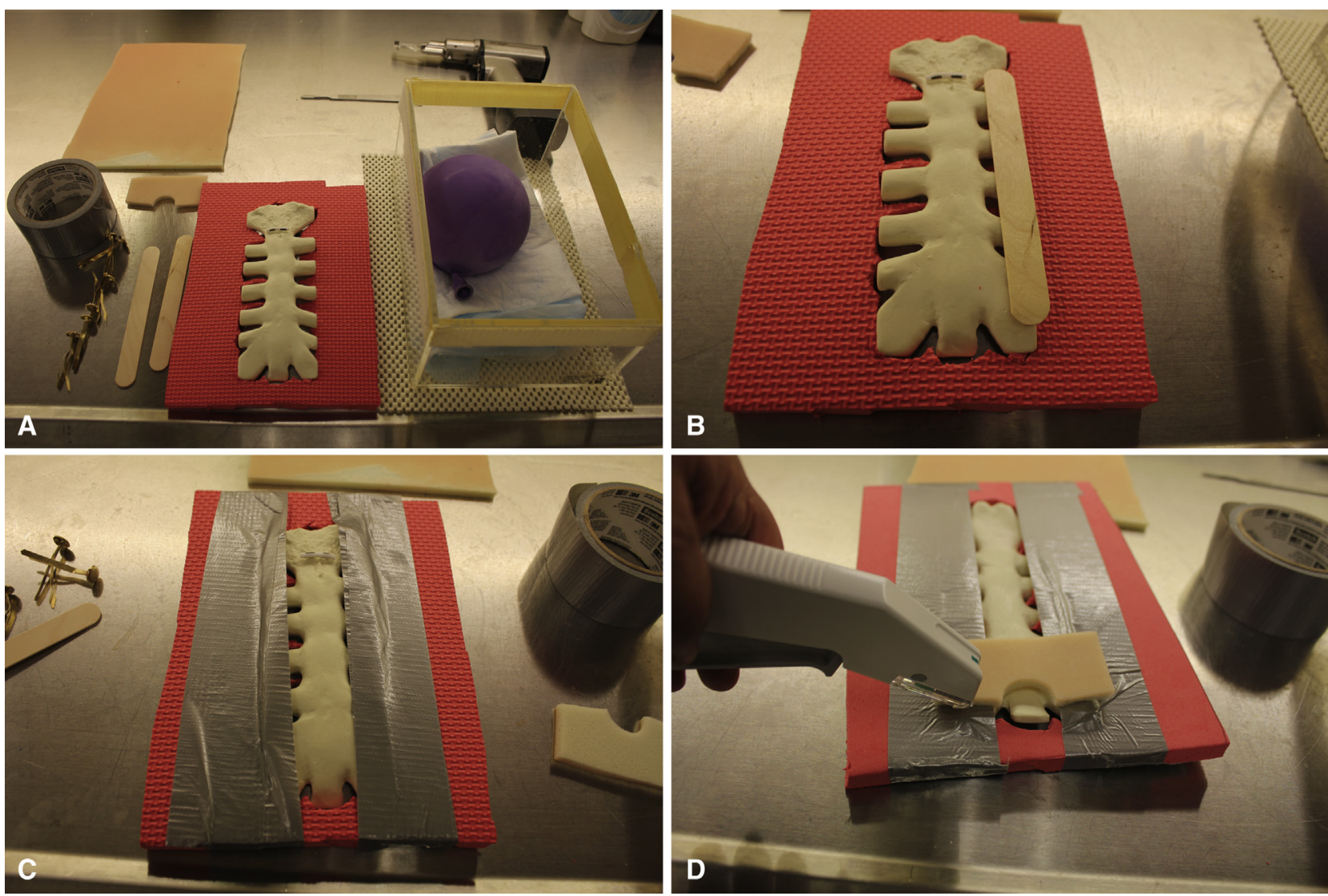

FIGURE 1. A, Materials required for the construction of the sternotomy model. B, The artificial sternal bone model (Sternum with cartilage 20PCF Solid Foam; Sawbones, Vashon Island, Wash) is encased in the red floor mat foam after cutting out the outline. The popsicle stick is placed approximately 0.5 to $1 \mathrm{~cm}$ lateral to the sternal edge. C, The popsicle sticks are secured to the foam with duct tape. D, An outline of the sternal notch using artificial skin (Dragon Skin 10; Smooth-On, Macungie, Pa) is stapled to the red foam. E, The water-filled balloon (to simulate a heart) is placed inside the acrylic box and a layer of cling wrap is sealed above the box (to simulate pericardium). F, All layers are secured together with the brass split pins. G, The sternum and all of the encompassing layers are secured to the box using tape and cling wrap. H, A profile view of all layers of the sternotomy model.

checklist provides a tool for assessment of trainee performance, and second, the checklist provides the trainee with a list of fundamental and salient steps to review. Checklists also allow trainees to mentally practice and review the steps of a procedure before performance of the skill. The ability to mentally practice a skill is paramount to the development of technical skills. ${ }^{22}$ For example, a randomized control trial by De La Garza and colleagues ${ }^{23}$ found that providing trainees with a procedural checklist enhanced knowledge acquisition when learning a new technical skill. Petrik and colleagues $^{24}$ found that use of a checklist decreased the omission of critical steps of weaning from cardiopulmonary bypass. $^{24}$ With the transition to competency-based medical education, assessment tools are refocusing on the development of task-specific checklists because they act as study aids and allow learners to focus on specific and salient steps of a technical task. ${ }^{9}$ Using our checklist as a foundation, future iterations may also be developed for more complex variations such as redo sternotomy and ministernotomy.
The interrater reliability during checklist scoring was fair to moderate. ${ }^{19}$ There are multiple factors that may be responsible for this. First, rater training or piloting of the checklist was not done before assessment of participants. Previous studies have demonstrated the importance of rater training and experience with assessment tools in improving interrater reliability. ${ }^{25-27}$ Because future iterations of the Bootcamp employ the median sternotomy training model and procedure checklist, the interrater reliability can be improved with training of raters and improved iterations of the checklist. Additionally, analysis of checklist items with recurrent poor interrater reliability and discussion with raters to ascertain sources of discrepancy may help elucidate whether rater training is sufficient, or whether modifications to the checklist are needed.

\section{Limitations}

There were several limitations in the present study. The raters responsible for assessing the participants in the study were not blinded, thus increasing the risk of bias during the 

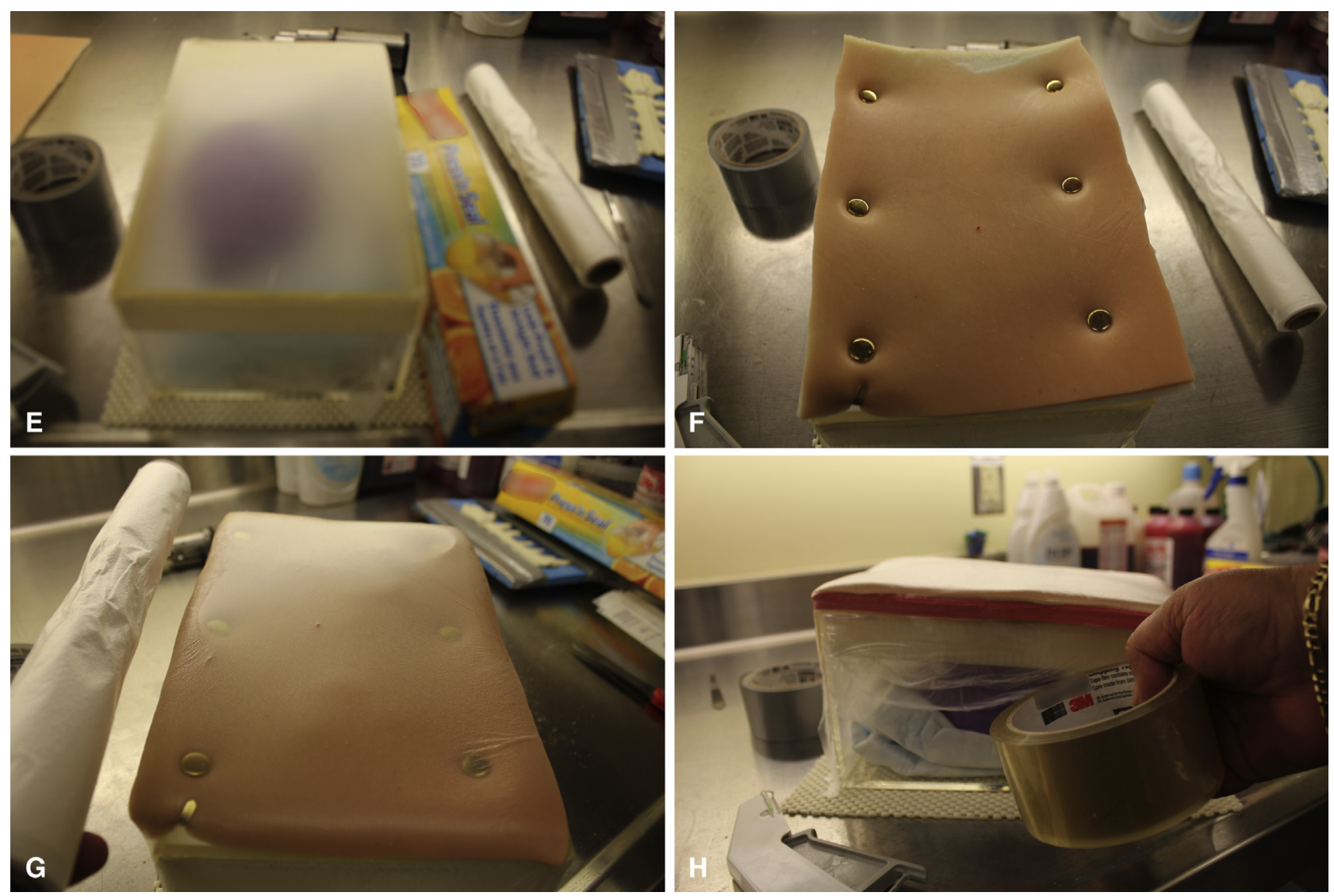

FIGURE 1. (Continued)

assessment of participants. Notably, there were no preexisting relationships between the raters and participants and thus bias in assessment was expected to be low. Future studies may consider videorecording participants' performance and using blinded raters to assess the participants

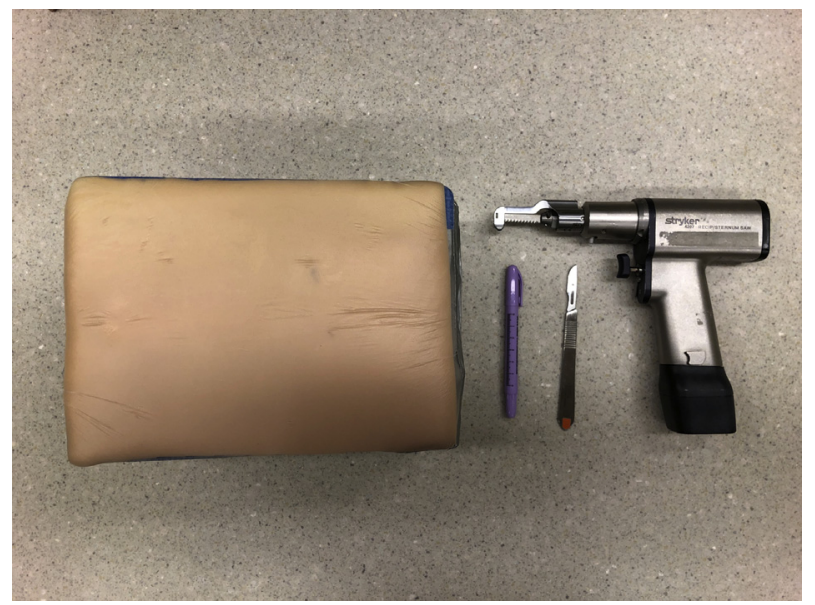

FIGURE 2. Materials required to perform the median sternotomy simulation. From left to right, the sternotomy model, a marking pen, a 10-blade scalpel, and a sternal saw.
TABLE 4. Demographic characteristics of study participants $(\mathbf{N}=13)$

\begin{tabular}{lc}
\hline \multicolumn{1}{c}{ Characteristic } & Result \\
\hline Training program & $13(100)$ \\
6-y Program & 0 \\
$\quad$ Postgeneral surgery & \\
Postgraduate year & $10(76.9)$ \\
1 & $2(15.4)$ \\
2 & $1(7.7)$ \\
$\geq 3$ & \\
Sex & $10(76.9)$ \\
Male & $3(23.1)$ \\
Female & \\
Years past completion of medical school & $8(61.5)$ \\
$\leq 1$ & $1(7.7)$ \\
$1-2$ & $4(30.8)$ \\
$\geq 2$ & \\
Previous postgraduate training in cardiac surgery & $3(23.1)$ \\
Yes & $10(76.9)$ \\
No & \\
Previous performance of median sternotomy & $1(7.7)$ \\
None & $5(38.5)$ \\
$1-5$ & $3(23.1)$ \\
$6-10$ & $4(30.8)$ \\
$\geq 10$ &
\end{tabular}

Values are presented as $\mathrm{n}(\%)$. 

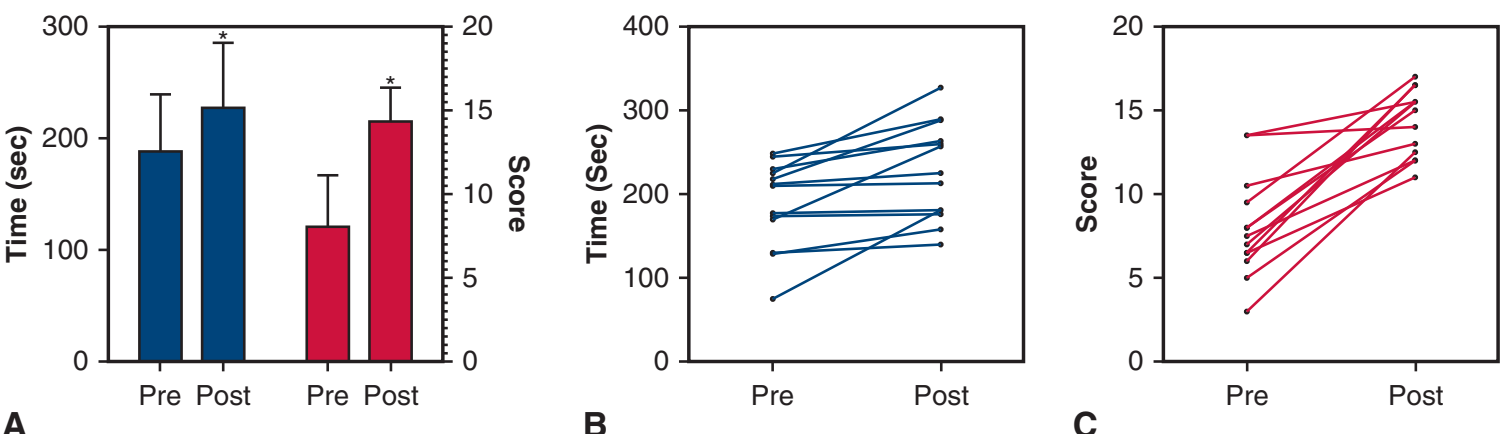

FIGURE 3. A, Time (in seconds) elapsed from the beginning to end of performance of simulated median sternotomy (blue histograms) and participant scores on the median sternotomy checklist (red histograms) before (Pre) and after (Post) viewing of the sternotomy video and reviewing of the sternotomy checklist. B, Individual performances for time required to perform the simulated sternotomy Pre and Post. C, Individual performances for checklist score Pre and Post. The error bars represent standard deviation. *Statistically significant at $P \leq .05$.

to reduce bias. ${ }^{26}$ Secondly, although inexpensive models like ours are easily acquired, they lack the realistic nature of human tissue. The majority of participants, however, did believe that the model was very realistic. Finally, a limitation of our study is the use of only local institutional staff as experts for the modified Delphi consensus method. Although the median sternotomy is a fairly standardized technique, there are standards and preferences that vary between institutions and thus applicability of our checklist may not be universal. Other institutions that consider adopting the sternotomy checklist may consider modifying the checklist for their own trainees based on institutional preferences.

\section{CONCLUSIONS}

An inexpensive simulation model paired with an instructional video led to improvement in the performance of a safe simulated median sternotomy. A checklist was developed for the assessment of median sternotomy performance in addition to providing trainees with a stepwise approach for this important skill. Overall, participants were very satisfied with the simulation model and found it beneficial to their learning.

\section{Conflict of Interest Statement}

The authors reported no conflicts of interest.

The Journal policy requires editors and reviewers to disclose conflicts of interest and to decline handling or reviewing manuscripts for which they may have a conflict of interest. The editors and reviewers of this article have no conflicts of interest.

\section{References}

1. Ribeiro IB, Ngu JMC, Lam BK, Edwards RA. Simulation-based skill training for trainees in cardiac surgery: a systematic review. Ann Thorac Surg. 2018;105: 972-82.

2. Malas T, Al-Atassi T, Brandys T, Naik V, Lapierre H, Lam BK. Impact of visualization on simulation training for vascular anastomosis. J Thorac Cardiovasc Surg. 2018;155:1686-93.
3. Feins RH, Burkhart HM, Conte JV, Coore DN, Fann JI, Hicks GL Jr, et al. Simulation-based training in cardiac surgery. Ann Thorac Surg. 2017;103:312-21.

4. Burkhart HM, Riley JB, Hendrickson SE, Glenn GF, Lynch JJ, Arnold JJ, et al The successful application of simulation-based training in thoracic surgery residency. J Thorac Cardiovasc Surg. 2010;139:707-12.

5. Ribeiro IB, Ngu JMC, Gill G, Rubens FD. Development of a high fidelity pressurized porcine beating heart simulator for cardiac surgery training. Perfus (United Kingdom). 2017;32:568-73.

6. Price J, Naik V, Boodhwani M, Brandys T, Hendry P, Lam BK. A randomized evaluation of simulation training on performance of vascular anastomosis on a high-fidelity in vivo model: the role of deliberate practice. J Thorac Cardiovasc Surg. 2011;142:496-503.

7. Anders Ericsson K. Deliberate practice and acquisition of expert performance: a general overview. Acad Emerg Med. 2008;15:988-94.

8. Pavlidis I, Zavlin D, Khatri AR, Wesley A, Panagopoulos G, Echo A. Absence of stressful conditions accelerates dexterous skill acquisition in surgery. Sci Rep. 2019;9:1747.

9. Wagner N, Fahim C, Dunn K, Reid D, Sonnadara RR. Otolaryngology residency education: a scoping review on the shift towards competency-based medical education. Clin Otolaryngol. 2017;42:564-72.

10. Martin JA, Regehr G, Reznick R, MacRae H, Murnaghan J, Hutchison C, et al. Objective structured assessment of technical skill (OSATS) for surgical residents. Br J Surg. 1997;84:273-8.

11. Shah AA, Aftab M, Tchantchaleishvili V, LaPar DJ, Stephens EH, Walters DM, et al. Characterizing the operative experience of cardiac surgical trainees: what are residents really doing in the operating room? Ann Thorac Surg. 2016;101: 2341-9.

12. Zeitani J, de Peppo AP, Moscarelli M, Guerrieri Wolf L, Scafuri A, Nardi P, et al. Influence of sternal size and inadvertent paramedian sternotomy on stability of the closure site: a clinical and mechanical study. J Thorac Cardiovasc Surg. 2006;132:38-42.

13. Trehan K, Kemp CD, Yang SC. Simulation in cardiothoracic surgical training: where do we stand? J Thorac Cardiovasc Surg. 2014;147: 18-24.e2.

14. Ramphal PS, Coore DN, Craven MP, et al. A high fidelity tissue-based cardiac surgical simulator. Eur J Cardiothorac Surg. 2005;27:910-6.

15. Hsu C-C, Sandford BA. The Delphi technique: making sense of consensus. Pract Assess Res Eval. 2007;12(10).

16. Dalkey N, Helmer O. An experimental application of the Delphi method to the use of experts. Manage Sci. 1963;9:458-67.

17. Amber JF, Gregory PM. Using the Delphi method for qualitative, participatory action research in health leadership. Int J Qual Methods. 2014;13:1-18.

18. Cohen J. A coefficient of agreement for nominal scales. Educ Psychol Meas. 1960;XX:37-46.

19. Landis JR, Koch GG. The measurement of observer agreement for categorical data. Biometrics. 1977;33:159-74.

20. Moulton CE, Regehr G, Mylopoulos M, MacRae HM. Slowing down when you should: a new model of expert judgment. Acad Med. 2007;82:109-16.

21. Dreyfus SE, Dreyfus HL. A five-stage model of the mental activities involved in directed skill acquisition. Available at: https://apps.dtic.mil/dtic/tr/fulltext/u2/ a084551.pdf. Accessed April 9, 2020. 
22. Cocks M, Moulton C-A, Luu S, Cil T. What surgeons can learn from athletes: mental practice in sports and surgery. J Surg Educ. 2014;71:262-9.

23. De La Garza JR, Schmidt MW, Kowalewski KF, Benner L, Müller PC, Kenngott HG, et al. Does rating with a checklist improve the effect of E-learning for cognitive and practical skills in bariatric surgery? A rater-blinded, randomized-controlled trial. Surg Endosc. 2019:33:1532-43.

24. Petrik EW, Ho D, Elahi M, Ball TR, Hofkamp MP, Wehbe-Janek H, et al. Checklist usage decreases critical task omissions when training residents to separate from simulated cardiopulmonary bypass. J Cardiothorac Vasc Anesth. 2014; 28:1484-9.

25. Gawad N, Fowler A, Mimeault R, Raiche I. The inter-rater reliability of technical skills assessment and retention of rater training. J Surg Educ. 2019;1-6.
26. Vassiliou MC, Feldman LS, Fraser SA, Charlebois P, Chaudhury P, Stanbridge DD, et al. Evaluating intraoperative laparoscopic skill: direct observation versus blinded videotaped performances. Surg Innov. 2007;14: 211-6.

27. Robertson RL, Vergis A, Gillman LM, Park J. Effect of rater training on the reliability of technical skill assessments: a randomized controlled trial. Can J Surg. 2018;61:405-11.

Key Words: surgical education, medical education, simulation, sternotomy 